\title{
Reliability and validity of two new instrument for measuring aspects of mental slowness in the daily lives of stroke patients
}

Citation for published version (APA):

Winkens, I., van Heugten, C. M., Fasotti, L., \& Wade, D. (2009). Reliability and validity of two new instrument for measuring aspects of mental slowness in the daily lives of stroke patients. Neuropsychological Rehabilitation, 19(1), 64-85. https://doi.org/10.1080/09602010801913650

Document status and date:

Published: 01/01/2009

DOI:

10.1080/09602010801913650

Document Version:

Publisher's PDF, also known as Version of record

Document license:

Taverne

Please check the document version of this publication:

- A submitted manuscript is the version of the article upon submission and before peer-review. There can be important differences between the submitted version and the official published version of record.

People interested in the research are advised to contact the author for the final version of the publication, or visit the DOI to the publisher's website.

- The final author version and the galley proof are versions of the publication after peer review.

- The final published version features the final layout of the paper including the volume, issue and page numbers.

Link to publication

\footnotetext{
General rights rights.

- You may freely distribute the URL identifying the publication in the public portal. please follow below link for the End User Agreement:

www.umlib.nl/taverne-license

Take down policy

If you believe that this document breaches copyright please contact us at:

repository@maastrichtuniversity.nl

providing details and we will investigate your claim.
}

Copyright and moral rights for the publications made accessible in the public portal are retained by the authors and/or other copyright owners and it is a condition of accessing publications that users recognise and abide by the legal requirements associated with these

- Users may download and print one copy of any publication from the public portal for the purpose of private study or research.

- You may not further distribute the material or use it for any profit-making activity or commercial gain

If the publication is distributed under the terms of Article 25fa of the Dutch Copyright Act, indicated by the "Taverne" license above, 


\section{Reliability and validity of two new instruments for measuring aspects of mental slowness in the daily lives of stroke patients}

leke Winkens , Caroline M. Van Heugten , Luciano Fasotti \& Derick T. Wade

To cite this article: leke Winkens, Caroline M. Van Heugten, Luciano Fasotti \& Derick T. Wade (2009) Reliability and validity of two new instruments for measuring aspects of mental slowness in the daily lives of stroke patients, Neuropsychological Rehabilitation, 19:1, 64-85, DOI: 10.1080/09602010801913650

To link to this article: https://doi.org/10.1080/09602010801913650

曲 Published online: 19 Dec 2008.

Submit your article to this journal $\longleftarrow$

山 Article views: 477

Q View related articles 두

4 Citing articles: 6 View citing articles 


\title{
Reliability and validity of two new instruments for measuring aspects of mental slowness in the daily lives of stroke patients
}

\author{
Ieke Winkens ${ }^{1,2}$, Caroline M. Van Heugten ${ }^{1,2}$, Luciano Fasotti ${ }^{3,4}$, \\ and Derick T. Wade ${ }^{1,5}$ \\ ${ }^{1}$ Vilans, Hoensbroek, The Netherlands, ${ }^{2}$ Institute Brain and Behaviour, \\ University of Maastricht, The Netherlands, ${ }^{3}$ Sint Maartenskliniek Research, \\ Development \& Education, Nijmegen, The Netherlands, ${ }^{4}$ NICI, Nijmegen \\ Institute for Cognition and Information, Nijmegen, The Netherlands, \\ ${ }^{5}$ Oxford Centre for Enablement, Oxford, UK
}

The objective of the study was to examine psychometric characteristics of two measures related to mental slowness experienced after stroke: One measure is aimed at performance on tasks, the other is a questionnaire evaluating perceived consequences of mental slowness. A group of 37 stroke patients and 33 matched controls were studied. A subgroup of 10 patients and 22 controls was observed by two independent raters to determine inter-rater reliability, a subgroup of 18 patients completed the questionnaire twice over a two-week interval to determine test-retest stability. Results showed that internal consistency was acceptable for the Mental Slowness Observation Test (Cronbach's $\alpha=.61$ and .73) and good for the Mental Slowness Questionnaire $(\alpha=.91)$. For the Observation Test, correlations between the results of the two raters ranged between .77 and .99 and intra-class correlation coefficients were between .86 and .99. For the Questionnaire, correlations between two test occasions ranged between .85 and .90 and intra-class correlation coefficients were between .91 and .95 . Correlations of between .52 and .67 were found between the Observation Test and neuropsychological tasks for speed

Correspondence should be sent to I. Winkens, Vilans, PO Box 192, 6430 AD Hoensbroek, The Netherlands. E-mail: i.winkens@ vilans.nl

The authors would like to thank Esther Habets and all the patients and employees of the rehabilitation centres Hoensbroeck (Hoensbroek), Blixembosch (Eindhoven), Leypark (Tilburg), De Hoogstraat (Utrecht) and Sint Maartenskliniek (Nijmegen) for their active collaboration in this study.

(C) 2008 Psychology Press, an imprint of the Taylor \& Francis Group, an Informa business http://www.psypress.com/neurorehab

DOI:10.1080/09602010801913650 
of information processing. The Questionnaire correlated most strongly with scores on tests for activities of daily living (ADL) functioning, and fatigue and depression (correlations ranged between .37 and .63). It was concluded that the two new instruments offer reliable and valid methods for measuring limitations in daily activities related to mental slowness and some of the consequences of mental slowness in terms of sense of time pressure, fatigue, depressive complaints and independent ADL functioning.

Keywords: Stroke; Mental slowness; Validity; Reliability; Daily life.

\section{INTRODUCTION}

Slowness of information processing, or mental slowness, is a prominent consequence of stroke (Ballard et al., 2003; Gerritsen, Berg, Deelman, VisserKeizer, \& Meyboom-De Jong, 2003; Rasquin, Lodder, Ponds, Winkens, \& Jolles, 2004). Several studies have shown that 50-70\% of patients with stroke show slowed performance on neuropsychological tests (Hochstenbach, Mulder, Van Limbeek, Donders, \& Schoonderwaldt, 1998; Rasquin, Verhey, Lousberg, Winkens, \& Lodder, 2002). Also, patients rate mental slowness high on a list of cognitive complaints (Hochstenbach, 1999; Visser-Keizer, Meyboom-De Jong, Deelman, Berg, \& Gerritsen, 2002).

Patients experience this slowness in several ways. It may mean that they perform activities with the unpleasant feeling of time pressure; the feeling that there is not enough time to think and act properly during task performance. In a previous study we found that slowed information processing affects a wide range of activities, especially in situations in which time pressure is present. Not only do stroke patients complain of difficulties when processing incoming information (e.g., when having a conversation or watching television), but they also report problems with memory, attention and learning. In addition patients experience physical and psychological complaints as a consequence of mental slowness, such as fatigue, higher irritability and emotionality, headaches and dizziness (Winkens, Van Heugten, Fasotti, Duits, \& Wade, 2006).

For neuropsychologists, slowness of information processing has traditionally been evaluated through standardised tests such as the Paced Auditory Serial Addition Task (PASAT), the Symbol Digit Modalities Test (SDMT) and reaction time tasks (Van Zomeren \& Spikman, 2003). However, we think that, in addition to a reduced speed of performance on simple neuropsychological tests such as reaction time tasks (which usually have a mental as well as a motor component), the concept of "mental slowness" can encompass at least two more aspects, possibly, but not necessarily, related to one another: (1) a perception that mental processing is slow, leading to a sense 
of time pressure, fatigue, etc; and (2) observed difficulties in performing time pressured daily activities where mental speed is important. Extrapolating the results of neuropsychological tests to the latter two aspects may be misleading (Ylvisaker, Hanks, \& Johnson-Greene, 2002). The experience of mental slowness in a patient's everyday functioning may not necessarily be concurrent with measured slowed information processing. Especially for the purpose of rehabilitation it is essential to gain insight into the functional problems experienced and factors related to them, which requires standardised instruments that specifically assess limitations in daily activities related to the experience of mental slowness.

In the present study we have developed a set of standardised observations that measure performance on time pressure tasks and a questionnaire that measures perceived consequences related to mental slowness in stroke patients. We present internal consistency, inter-rater and test-retest reliability, and construct validity of these newly developed instruments.

\section{METHOD}

\section{Participants}

Subjects were recruited from the stroke population of five rehabilitation centres in The Netherlands where patients are admitted to a rehabilitation centre when there are complex sensory-motor, cognitive and/or behaviour problems requiring a multidisciplinary rehabilitation approach. Most patients are younger than 65 years, able to follow an intensive rehabilitation programme and are expected to return to their home situation after rehabilitation. This means that the patients are expected to have sufficient learning ability, are sufficiently motivated and have adequate informal care at home (Synchron, 1996).

For this study, there were no further inclusion criteria. Psychologists were asked to recruit patients with stroke, but not necessarily suffering from mental or cognitive slowness. Patients were excluded if they were younger than 18 years, were less than 6 weeks post-stroke, had suffered from disabling psychiatric disease, had been hospitalised for substance abuse, had other medical or neurological diseases, or had such severe cognitive, communicative, physical or psychological problems that they were unable to perform a neuropsychological assessment (based on the clinical judgement of the treatment team).

Healthy controls were recruited from the personal environment of the researchers. They were matched to the patient group on age, sex and level of education, and were free from present or previous brain injury. Exclusion criteria were the same as for the patient group. 
The research protocol was approved by the Medical Ethics Board of each participating rehabilitation centre and informed consent was obtained from all participants.

\section{Measures}

Two new instruments were developed for use with patients who experienced mental slowness: one observed performance on specific activities, the other asked patients to quantify the experience of mental slowness.

\section{Mental Slowness Observation Test (MSOT)}

Based on the previous study (Winkens et al., 2006) and other literature (Owsley, Sloane, McGwin, \& Ball, 2002) we developed an Observation Test. The test initially consisted of five tasks that are commonplace for most people, are brief, amenable to accurate timing and easily standardised. The tasks were specifically designed to measure performance in time pressure situations: Patients are required to adequately handle incoming information and to work within certain time limits. Examples of the tasks are following a route description, making a telephone call, or looking up telephone numbers. Appendix 1 lists the instructions for each individual task. Instructions were paced or repeated when requested.

Two tasks had a preset maximum time, i.e., subtask 3 (sorting money, 5 minutes) and subtask 5 (looking up telephone numbers, 10 minutes): if the subject did not complete the task within this time period, the item was terminated. Otherwise the tester recorded the time needed to perform each task (Time score), and the number of elements correctly achieved (Elements score). The maximum score per task is 10 , the maximum total score is 50 .

\section{Mental Slowness Questionnaire (MSQ)}

The Questionnaire consists of 21 items examining different kinds of daily activities that are likely to be related to mental slowness. Examples of the items are: "I have trouble following a conversation", or "I have trouble doing two things at the same time". (Appendix 2.)

Each item is scored on a 5-point frequency scale ranging from 0: "this never happens" to 4: "this happens often". The maximum total score is 84 . Each problem is also scored on a 3-point severity scale ranging from 0 : "not troublesome", to 2: "very troublesome". For this scale, the maximum total score is 42 . Finally we multiplied the score on the frequency scale by the score on the severity scale. For this weighted scale the maximum total score is 168 . 
In addition, several neuropsychological tests for speed of information processing were used to objectify the presence of measured cognitive slowness and its relationship to perceived mental slowness.

- The Paced Auditory Serial Addition Task (PASAT; Gronwall \& Sampson, 1974), presented at a pacing with a $3.2 \mathrm{sec}$ interstimulus interval.

- Symbol Digit Modalities Test (SDMT; Smith, 1982)

- Simple Reaction Time Task, developed for this study: Subjects performed the task on a pocket PC. Subjects touched the screen until a stimulus appeared then withdrew from the screen as fast as possible. Reaction times were measured.

The patient group also completed tests for:

- Memory: Auditory Verbal Learning Test (AVLT; Brand \& Jolles, 1985).

- Attention: Trail Making Test A and B (TMT; Reitan, 1958), and

- Stroop Color-Word Task (Houx, Jolles, \& Vreeling, 1993).

- ADL functioning: Barthel Activities of Daily Living (ADL) Index (Collin, Wade, Davies \& Home, 1988).

- Fatigue: Fatigue Severity Scale (Krupp, LaRocca, Muir-Nash, \& Steinberg, 1989).

- Depression: Center for Epidemiologic Studies Depression Scale (CESD; Shinar et al., 1986)

This was to investigate whether performance on these tests would interfere with performance on the two new tests.

\section{Procedure}

All subjects who participated in the study were informed about the purpose of the study and their right to withdraw from the study at any stage. They were then asked to provide demographic information, including their age, level of education and medical history. All 37 stroke patients completed the entire test battery described above. The 33 controls were tested in a single session which consisted only of the Mental Slowness Observation Test, Mental Slowness Questionnaire and measures of cognitive speed.

For several reasons only a subgroup of 10 patients and 22 controls completed the Observation Test while they were observed by two raters 
simultaneously: Patients did not always give permission, and in daily clinical practice it was just not always possible to have two raters present at the same time. In addition only 18 patients completed the Questionnaire a second time two weeks later: either patients did not give permission or did not return the Questionnaire.

The measurements were performed at the rehabilitation centre, the research institute or at home. Each patient was tested by one of two neuropsychologists in sessions of one and a half to two hours (in case of fatigue patients were tested twice, in two one-hour sessions). The Questionnaire was administered twice by the same neuropsychologist.

\section{Statistical analyses}

The characteristics of the subjects and the results of the assessment procedure are presented using descriptive statistics. Independent samples $t$-tests, MannWhitney $U$ tests and $\chi^{2}$ tests were applied to determine differences between the two groups on each of the relevant demographic and test variables. Score distribution plots were used to describe differences between the two groups on the Observation Test and the Questionnaire.

Internal consistency of the tests was assessed by computing Cronbach's alpha (Haan, 1994). Inter-rater reliability and test-retest reliability were measured using simple correlation coefficients (Pearson or Spearman) (Heaton et al., 2001), and intra-class correlation coefficients (Van Heugten, 1998). Simple correlation coefficients were also used to investigate construct validity. Alpha was set at .05 .

SPSS version 12.0 package was used for statistical analysis.

\section{RESULTS}

Seventy subjects were included in the study between July 2004 and July 2005: 37 stroke patients and 33 controls. The patient group included 26 men and 11 women with a mean age of 54.8 years $(S D=12.1)$. Eleven patients had received higher education, 11 secondary, and 15 primary (education grades ranged from 1: elementary school to 8: university degree; Jolles, Houx, Van Boxtel, \& Ponds, 1995.) Fourteen patients had a left hemisphere stroke, 18 had a right hemisphere stroke and for five patients localisation of stroke was not specifically mentioned in their medical files. Thirty-one patients had suffered an ischaemic stroke, four had suffered a haemorrhage, and two had a post-operative infarct after haemorrhage. Twelve patients had recurrent stroke, 25 were first-ever stroke patients. Mean time since stroke was 234 days $(S D=160$; range $=6$ weeks to 22.9 months). Mean Barthel score was $18.9(S D=1.9)$. Twenty-eight patients had a score of 19 or 20; the patient group was not very disabled. 
The control group included 17 males and 16 females and had a mean age of 49.8 years $(S D=10.1)$. Fifteen subjects had received higher education, nine secondary, and nine primary education. Statistical testing revealed that the control and patient group were well matched with respect to sex $\left(\chi^{2}=2.6\right.$, $p>.05)$, age $(t=-1.9, p>.05)$ and education grade $(Z=-1.4, p>.05)$.

\section{Neuropsychological performance}

Table 1 shows the results of both the patient and control group on each of the relevant test variables. The patient group performed significantly more slowly on all measures of information processing speed: SDMT written $(t=7.4$, $p<.01)$, SDMT verbal $(t=7.2, p<.01)$, Simple Reaction Time Task $(Z=-4.2, p<.01)$ and PASAT $(t=5.1, p<.01)$.

\section{Mental Slowness Observation Test and Mental Slowness Questionnaire}

Table 2 shows that the patient group scored significantly lower (Elements score) on two of the subtasks (subtask 2, making a telephone call: $Z=-3.4, p<.01$; subtask 5, looking up telephone numbers: $Z=-2.8, p<.05$ ). One of these tasks was time limited, the other, however, was not. The patient group performed the other subtasks just as well as the control group. However,

TABLE 1

Neuropsychological test performance

\begin{tabular}{lcc}
\hline & $\begin{array}{c}\text { Patient group }(N=37) \\
\text { Mean }(S D)\end{array}$ & $\begin{array}{c}\text { Control group }(N=33) \\
\text { Mean }(S D)\end{array}$ \\
\hline SDMT written & $28.4(10.4)$ & $46.6(10.0)^{* *}$ \\
SDMT verbal & $35.9(11.6)$ & $55.2(10.8)^{* *}$ \\
Simple Reaction Time Task & $0.51(0.58)$ & $0.29(0.04)^{* *}$ \\
PASAT & $35.3(9.6)$ & $48.3(10.9)^{* *}$ \\
AVLT (total) & $40.1(11.6)$ & \\
TMT A (time in seconds) & $62.8(38.1)$ & \\
TMT B (time in seconds) & $153.9(112.8)$ & \\
STROOP 1 (time in seconds) & $66.2(25.5)$ & \\
STROOP 2 (time in seconds) & $89.4(42.8)$ & \\
STROOP 3 (time in seconds) & $156.3(74.0)$ & \\
FSS total (min $=9$, max $=63)$ & $31.5(13.1)$ & \\
FSS mean score $(\max =7)$ & $3.5(1.5)$ & \\
CES_D (min $=0$, max $=60)$ & $13.4(8.0)$ & \\
\end{tabular}

${ }^{* *} p<.01$.

SDMT $=$ Symbol Digit Modalities Test; PASAT $=$ Paced Auditory Serial Addition Task; AVLT $=$ Auditory Verbal Learning Test; TMT $=$ Trail Making Test; FSS = Fatigue Severity Scale; CES_D = Centre for Epidemiologic Studies Depression Scale. 
TABLE 2

Test results

\begin{tabular}{|c|c|c|c|}
\hline Test variable & & $\begin{array}{l}\text { Patient group } \\
\quad(N=37) \\
\text { Mean }(S D)\end{array}$ & $\begin{array}{l}\text { Control group } \\
\quad(N=33) \\
\text { Mean }(S D)\end{array}$ \\
\hline \multicolumn{4}{|l|}{ Mental Slowness Observation Test } \\
\hline \multirow[t]{2}{*}{ Total score over five tasks } & Elements correct & $39.1(8.1)$ & $43.2(4.9)$ \\
\hline & Time in seconds & $1232.3(304.6)$ & $815.8(197.0)^{* *}$ \\
\hline \multirow[t]{2}{*}{ Total score over four tasks } & Elements correct & $33.0(7.0)$ & $36.4(4.3)$ \\
\hline & Time in seconds & $1045.3(302.9)$ & $616.4(189.8)^{* *}$ \\
\hline \multirow[t]{2}{*}{ Subtask 1: Route description } & Elements correct & $9.1(2.1)$ & $8.5(2.3)$ \\
\hline & Time in seconds & $223.4(93.1)$ & $130.9(50.6)^{* *}$ \\
\hline \multirow[t]{2}{*}{ Subtask 2: Telephone call } & Elements correct & $8.0(2.5)$ & $9.4(1.8)^{* *}$ \\
\hline & Time in seconds & $174.1(84.5)$ & $134.6(31.4)^{*}$ \\
\hline \multirow[t]{2}{*}{ Subtask 3: Sorting money } & Elements correct & $8.9(2.3)$ & $9.6(0.8)$ \\
\hline & Time in seconds & $199.7(65.8)$ & $118.5(37.0)^{* *}$ \\
\hline \multirow[t]{2}{*}{ Subtask 4: Radio news } & Elements correct & $6.2(2.4)$ & $6.7(2.2)$ \\
\hline & Time in seconds & $187.1(33.2)$ & $193.7(23.5)$ \\
\hline \multirow[t]{2}{*}{ Subtask 5: Telephone numbers } & Elements correct & $7.0(3.4)$ & $8.9(2.2)^{*}$ \\
\hline & Time in seconds & $448.2(145.9)$ & $232.3(128.9)^{* *}$ \\
\hline \multicolumn{4}{|l|}{ Mental Slowness Questionnaire } \\
\hline \multirow[t]{3}{*}{ Total score } & Frequency & $34.5(20.5)$ & $7.5(10.2)^{* *}$ \\
\hline & Severity & $16.6(11.5)$ & $3.2(5.1)^{* *}$ \\
\hline & Frequency $\times$ severity & $52.4(39.5)$ & $7.6(15.4)^{* *}$ \\
\hline
\end{tabular}

${ }^{*} p<.05 ;{ }^{* *} p<.01$.

the time taken to perform these tasks clearly discriminated the patient group from the control group: The patient group was slower than the control group (Time score) on the total Observation Test and on each single subtask, with the exception of task four (listening to the radio news) (total: $Z=-5.3, p<.01$; subtask 1: $t=-5.1, p<.01$; subtask $2: t=-2.5$, $p<.05$; subtask 3: $Z=-5.3, p<.01$; subtask 5: $Z=-5.3, p<.01$ ). Performance of listening to the radio news (task 4) was the only task that did not discriminate the patient group from the control group on any of the scores. We reanalysed the data after leaving out subtask 4 . The results were not very different (Table 2: total: $Z=-5.6, p<.01$ ). We therefore decided to perform further analyses without subtask 4 .

Table 2 also shows the mean scores of both groups on the Questionnaire. The patient group scored significantly higher than the control group on all three scales of the Questionnaire: they had more complaints and were more severely disturbed by them (frequency: $Z=-5.12, p<.01$; severity: $Z=-5.04, p<.01$; frequency $\times$ severity: $Z=-5.17, p<.01$ ).

Figures 1 and 2 show the score distributions for both groups on the Mental Slowness Observation Test. The figures show that there were outliers for both 


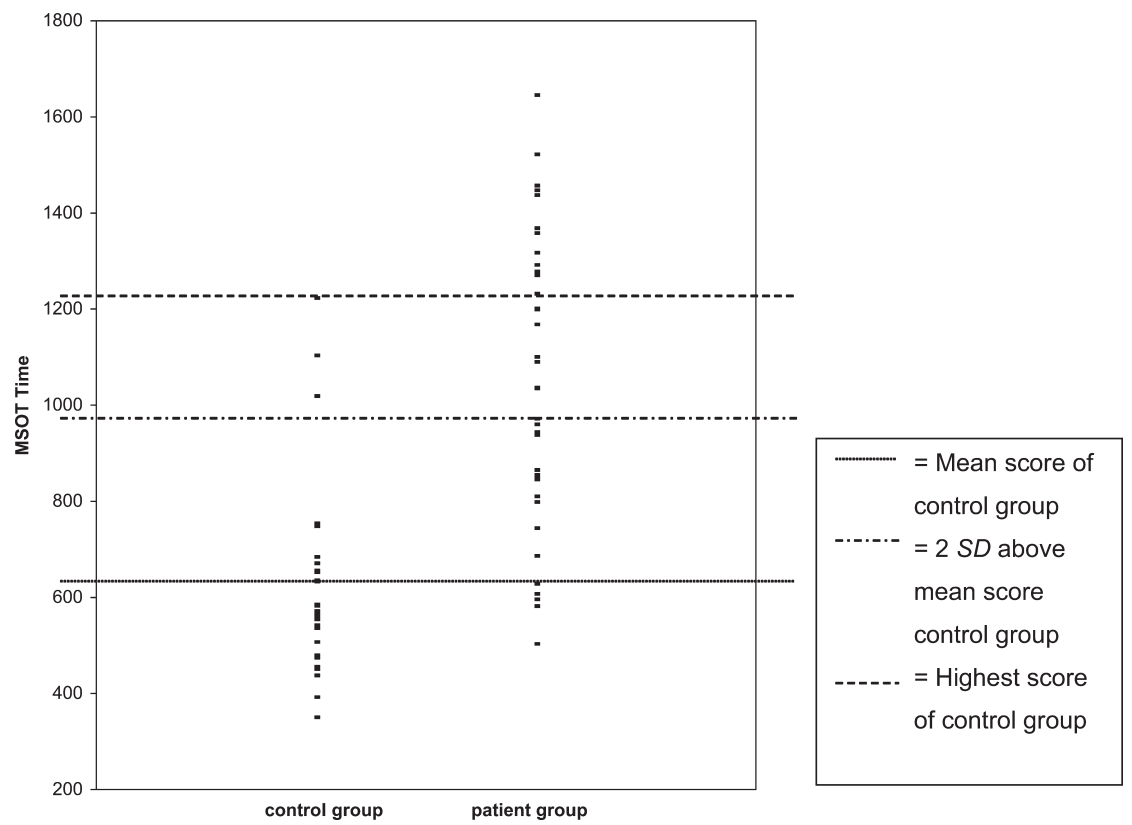

Figure 1. Score distributions for both groups on the Time score of the Mental Slowness Observation Test

the control and the patient group. However, removing the outliers did not lead to significantly different results. Figure 1 shows that $89 \%(n=32)$ of the patients were slower than the mean Time score of the control group; 53\% $(n=19)$ were $2 S D$ or more slower than the mean Time score of the control group, and 33\% $(n=12)$ of the patients were slower than the slowest person from the control group. Figure 2 shows that $49 \%(n=18)$ of the stroke patients scored below the mean Elements score of the control group; $24 \%(n=9)$ scored $2 S D$ or more below the mean score of the control group, but only two patients actually scored below the lowest score of the controls.

Figure 3 shows the score distributions for both the patient and control groups on the frequency x severity scale of the Mental Slowness Questionnaire. The scores of the stroke patients show considerably more variation than those of the control group: Patients scored across the total range of possible scores. In addition Figure 3 shows that $84 \%(n=31)$ of the patients scored above the mean score of the control group, that $59 \%(n=22)$ of the patients scored $2 S D$ or more above the mean score of the control group, and that $22 \%(n=8)$ had scores above the highest score of the controls. 


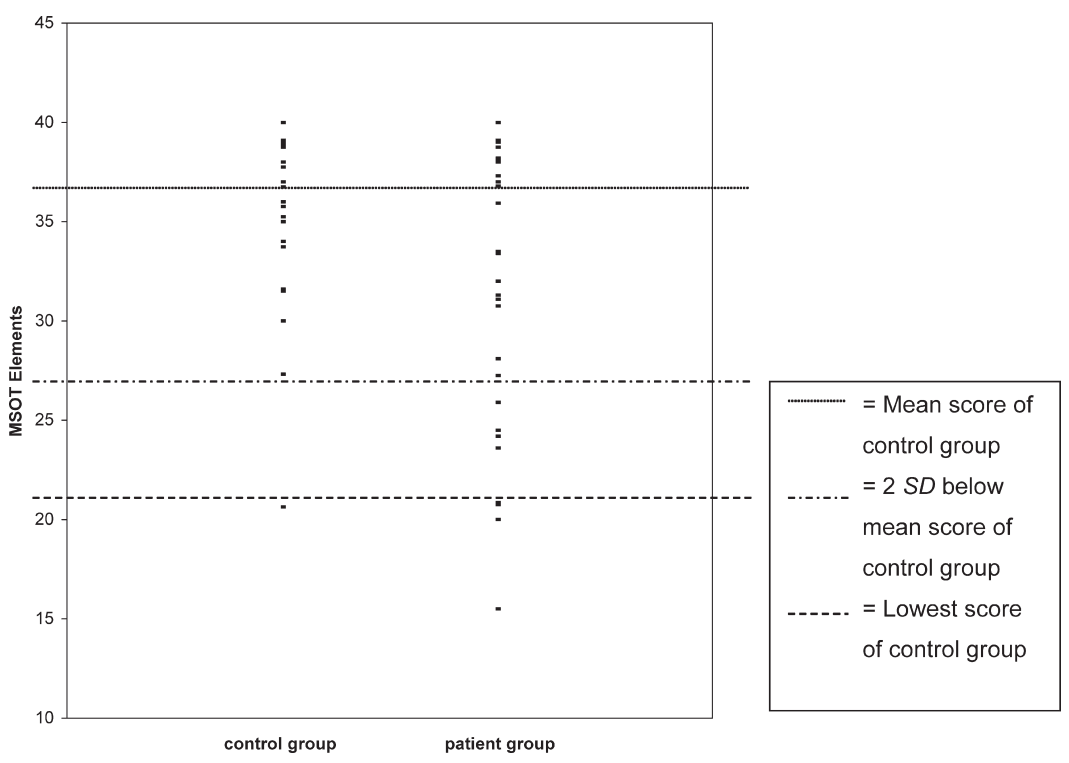

Figure 2. Score distributions for both groups on the elements score of the Mental Slowness Observation Test

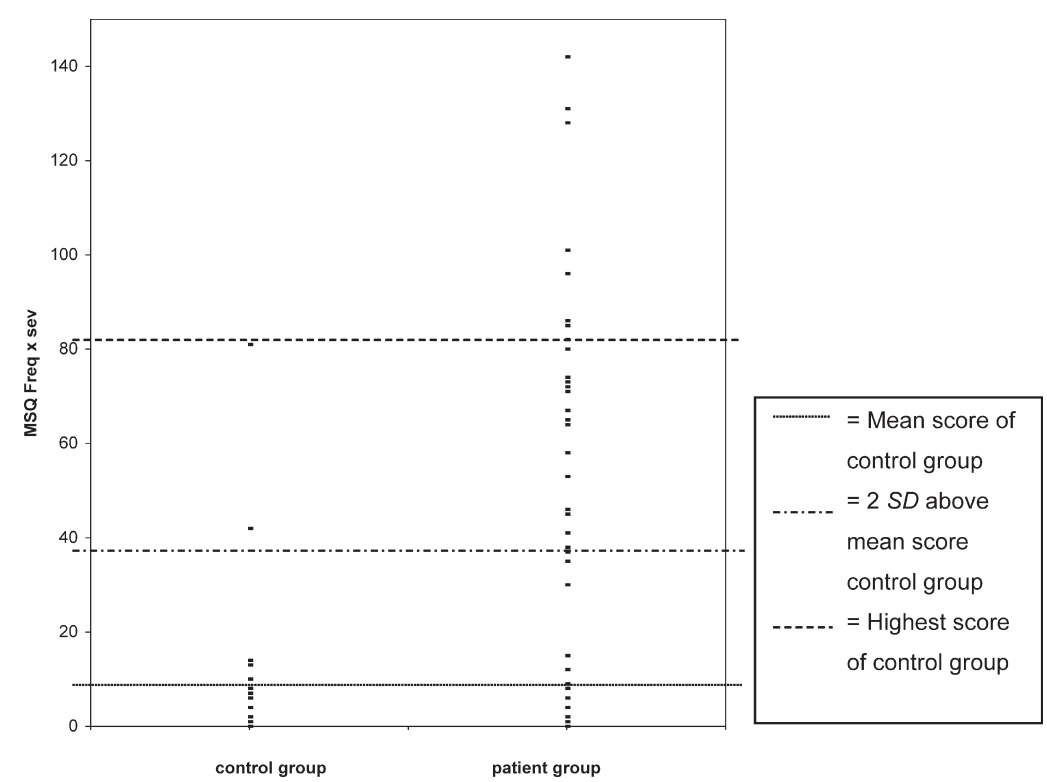

Figure 3. Score distributions for both groups on the frequency $\times$ severity scale of the Mental Slowness Questionnaire 


\section{Internal consistency of the MSOT and MSO}

After omitting subtask 4, Cronbach alpha values for the Observation Task ranged from .61 for the Elements score to .73 for the Time score. The Questionnaire had an alpha value of .91. None of the items in the Questionnaire lowered the alpha value.

\section{Inter-rater reliability of MSOT}

Table 3 shows that rater 2 scored systematically higher than rater 1 on subtask 1 (following a route description) and on the Total score over 4 tasks (subtask 1: $t=-2.2 . p<.05$; total: $t=-2.2, p<.05$ ). However, the differences were only small. The table also shows the correlations between the results of the two raters and the intra-class correlation coefficients suggesting good inter-rater reliability (Heaton et al., 2001; Van Heugten, 1998).

\section{Test-retest reliability of the MSO}

Table 4 shows that there were no systematic differences between the scores on test occasion 1 and test occasion 2 regarding all three scales of the Questionnaire. Correlations ranged between .85 and .90 and intra-class correlation coefficients ranged between .91 and .95 .

\section{Construct validity}

All tests for speed of information processing, except the Simple Reaction Time Task, correlated significantly with the total Time score of the Mental Slowness Observation Test (SDMT written: $r=-.67, p<.01$; SDMT verbal: $r=-.52, p<.01$; PASAT: $r=-.58, p<.01)$. The SDMT also had significant correlations with the total Elements score of the MSOT

TABLE 3

Inter-rater reliability estimates of the Mental Slowness Observation Test $(N=32)$

\begin{tabular}{|c|c|c|c|c|}
\hline Test variable & $\begin{array}{c}\text { Rater } 1 \\
\text { Mean }(S D)\end{array}$ & $\begin{array}{c}\text { Rater } 2 \\
\text { Mean }(S D)\end{array}$ & $\begin{array}{l}\text { Correlation } \\
\text { coefficients }\end{array}$ & $\begin{array}{l}\text { Intra-class } \\
\text { correlation } \\
\text { coefficients }\end{array}$ \\
\hline $\begin{array}{l}\text { Total score over four tasks } \\
\text { (Elements correct) }\end{array}$ & $33.8(7.0)$ & $34.31(6.7)^{*}$ & $.98^{* *}$ & $.99^{* *}$ \\
\hline Subtask 1: Route description & $7.9(2.7)$ & $8.3(2.7)^{*}$ & $.94^{* *}$ & $.97^{* *}$ \\
\hline Subtask 2: Telephone Call & $8.7(2.4)$ & $8.9(2.1)$ & $.97^{* *}$ & $.98^{* *}$ \\
\hline Subtask 3: Sorting Money & $9.0(2.2)$ & $9.0(2.1)$ & $.90^{* *}$ & $.99^{* *}$ \\
\hline Subtask 4: Radio news & $6.4(2.1)$ & $6.0(2.4)$ & $.77^{* *}$ & $.86^{* *}$ \\
\hline Subtask 5: Telephone numbers & $8.3(2.7)$ & $8.2(2.8)$ & $.99^{* *}$ & $.99^{* *}$ \\
\hline
\end{tabular}

${ }^{*} p<.05 ;{ }^{* *} p<.01$. 
TABLE 4

Test-retest reliability estimates of the Mental Slowness Questionnaire $(N=18)$

\begin{tabular}{llllc}
\hline Test variable & $\begin{array}{c}\text { Test occasion 1 } \\
\text { Mean }(S D)\end{array}$ & $\begin{array}{c}\text { Test occasion 2 } \\
\text { Mean }(S D)\end{array}$ & $\begin{array}{c}\text { Correlation } \\
\text { coefficients }\end{array}$ & $\begin{array}{c}\text { Intra-class } \\
\text { correlation } \\
\text { coefficients }\end{array}$ \\
\hline Frequency & $45.0(13.9)$ & $44.3(18.6)$ & $.85^{* *}$ & $.91^{* *}$ \\
Severity & $22.6(9.0)$ & $23.4(9.9)$ & $.90^{* *}$ & $.95^{* *}$ \\
Frequency $\times$ Severity & $65.4(36.2)$ & $64.1(40.2)$ & $.89^{* *}$ & $.94^{* *}$ \\
\hline
\end{tabular}

${ }^{* *} p<.01$.

(SDMT written: $r=.66, p<.01$; SDMT verbal: $r=.59, p<.05$ ). Patients who were slow on tests for speed of information processing, made more mistakes on the Mental Slowness Observation Test, and needed more time to complete the test. In addition, several other neuropsychological tests had significant correlations with both the total Time score of the Observation Test (AVLT: $r=-.43, p<.01$; TMT A: $r=.57, p<.05$; TMT B: $r=.69, p<.01$ ). and the total Elements score (TMT A: $r=-.59, p<$ .01 ; TMT B: $r=-.59, p<.01$; Stroop card 1: $r=-.33, p<.05)$. And finally, the Elements score of the Observation Test correlated significantly with the Barthel ADL Index $(r=.40, p<.05)$ and Center for Epidemiologic Studies Depression scale $(r=.35, p<.05)$, indicating that patients with depressive complaints and less independence in ADL functioning performed worse on the Observation Test.

The Mental Slowness Questionnaire did not correlate with the Mental Slowness Observation Test, showing that patients with few or no complaints on the Questionnaire are not necessarily the ones that do well on the Observation Test. In addition the Questionnaire did not correlate with any of the neuropsychological tests for speed of information processing, memory or attention. However, the Questionnaire had significant correlations with the Barthel ADL Index $(r=.37, p<.05)$, Fatigue Severity Scale $(r=.41$, $p<.05)$ and Centre for Epidemiologic Studies Depression Scale $(r=.63$, $p<.01)$.

\section{DISCUSSION}

In the present study it was found that stroke patients need considerably more time to complete four out of five subtasks of a newly developed Mental Slowness Observation Test than do matched controls without stroke. Moreover, patients make more mistakes on two out of five subtasks. One of these tasks was time-limited, the other was not. This might lead one to argue that tasks for measuring mental slowness should evaluate only time. 
However, the results showed no clear-cut speed-accuracy trade off: such a trade off would imply that subjects will perform better if they take enough time for the task at hand. But this is not what we have found: Some subjects were very fast and made no or few mistakes; others worked very fast but performed badly. Therefore we suggest using both the Time and Elements scores.

The finding that performances on one subtask - listening to a radio broadcast - were only slightly different between patients and controls may be explained as follows: This subtask, contrary to the other subtasks, was not a self-paced task; participants listened to radio news that was recorded on a tape, without opportunity to interrupt or ask for repetition. However, contrary to our expectations, patients did not make more mistakes than controls. We therefore have removed this task from the final version of our Observation Test.

The study also found that stroke patients given a newly developed questionnaire, the Mental Slowness Questionnaire, rated that they had more problems than controls and that they were more troubled by their difficulties. The results confirm our hypotheses and validate the Observation Test and Questionnaire.

\section{Clinimetric properties}

Both the Observation Test and the Questionnaire had reasonable clinimetric properties. Internal consistency was acceptable for the Observation Test and good for the Mental Slowness Questionnaire. The simple correlation coefficients and intra-class correlation coefficients indicated good reliability for both the Observation Test and the Questionnaire, suggesting that observation by two independent observers or responding to the Questionnaire on two different occasions should lead to similar conclusions.

We had no relevant external criterion for measuring mental slowness in daily life. However, to be able to say anything about the validity of the Observation Test, we used the second best criterion and correlated observed performance with the Observation Test to the results of neuropsychological tasks for speed of information processing. Strong correlations were found implying that the Observation Test indeed measures at least one component of the construct of mental slowness. However, we were interested in measuring the other two aspects of slowness, namely the perception that mental processing is slow, and observed difficulties in daily activities where time pressure is important. Although we are aware that we could not compare the new instrument to a gold standard measuring mental slowness in everyday situations, we do believe that this instrument comes closer to our goal than standardised neuropsychological tests. In addition we are aware that the correlations between the Observation Test and tests of cognitive 
slowness do not exclude the relevance of other functional abilities in the execution of complex daily life tasks under time pressure. Speed is a property of all cognitive and neurological functions and a resource of cognitive functioning in general (Salthouse, 1996; Spikman, Van Zomeren, \& Deelman, 1996). It manifests itself, or can be perceived, through its impact upon several mental processes such as memory, attention or executive functioning. It is not possible to study mental slowness without studying subjective or objective change in other (cognitive) functions and it can be expected that one would also find significant relationships with several other neuropsychological tests such as Trail Making Task A and B, the Auditory Verbal Learning Task and a test for independence in ADL functioning. In addition, one must be aware that, for example, motor abilities, aphasia and neglect (which we did not specifically measure) also play a decisive role in the performance of daily life tasks. Although we excluded patients with severe problems, it is evident that even mild deficits may hamper patients in their performance.

However, the aim of the study was the construction of a practical rehabilitation-based instrument and a structured observation test reflecting the everyday consequences of mental slowness and time pressure. The significant correlations with structured speed tasks and the good inter-rater reliability show that this test is a useful measure reflecting the everyday consequences of mental slowness.

The results of the Questionnaire did not correlate with the results of the Observation Test or any of the other neuropsychological tests for speed of information processing. This could be for several reasons. First it may be due to an awareness problem of the patient, which would be in accordance with previous studies that showed that subjective self-reported complaints do not always match with task performance (Ponds, 1998; Schofield et al., 1997). Second, we think that it is possible for patients to perform daily life tasks normally, even when they are indeed slower. This could be due to, for example, appropriate use of strategies. Lastly, patients may feel they have become slower than before, while still being able to perform at an average or above average level.

Thus the questionnaire does not primarily measure the actual limitation of activities caused by mental slowness. It does measure a patient's perception of the impact of mental slowness upon his or her performance, manifest as a change in well-being. This may encompass a wide variety of complaints: patients may complain of slowness when they compare performance to their expectation, of fatigue and tiredness arising from the extra cognitive input required, or of low mood because of poor performance. Our finding that the Questionnaire correlated most strongly with scores on scales for independent ADL functioning, fatigue and depression is therefore not surprising. Patients who are less independent in ADL performance attribute this to 
slowness, and feel more fatigued and depressed, but it is not possible to disentangle the complex inter-relationships between cognitive functioning, mood, fatigue and limitation on activities.

We think the results suggest that the two sets of data measure different aspects of the construct of mental slowness: One measures the subjective perception that mental processing is slow (leading to a sense of time pressure and feeling that more effort is needed, to complaints of fatigue, etc.), the other measures observed difficulties in performing daily activities with a significant time pressure component.

\section{Limitations}

Some limitations of this study need to be considered. First, the study sample was a selected group of patients admitted to a rehabilitation centre. In The Netherlands, only $10 \%$ of the stroke population is eligible for rehabilitation (Van Exel, Koopmanschap, Van Wijngaarden, \& Scholte Op Reimer, 2003). This does not allow generalisation of the results of this study to all stroke patients, especially those who are older or those with a less favourable prognosis.

Second, the new instruments should not be considered "gold standards" for diagnosing mental slowness after stroke. These instruments aim to quantify the extent of mental slowness, not to determine its presence. Before using the instruments as diagnostic tools, future studies should focus on several other clinimetric properties such as sensitivity, specificity and divergent validity and on the usefulness of these instruments for groups of patients different from the one described in this study.

\section{Conclusions}

In conclusion, both instruments offer reasonably reliable and valid methods for assessing two aspects of the construct of mental slowness as experienced by patients after stroke: the observation task measures actual performance of time pressure activities experienced in normal life; and the questionnaire measures the patient's subjective experience of slowness and its consequences in terms of experienced time pressure, fatigue, changes in emotion and ADL functioning. Although for both measures sensitivity to changes due to treatment still has to be proven, they might be useful tools in studies evaluating the effectiveness of treatments and especially the generalisability of these effects to everyday life. 


\section{REFERENCES}

Ballard, C., Stephens, S., Kenny, R. A., Kalaria, R., Tovee, M., \& O’Brien, J. (2003). Profile of neuropsychological deficits in older stroke survivors without dementia. Dementia and Geriatric Cognitive Disorders, 16, 52-56.

Brand, P. A., \& Jolles, J. (1985). Learning and retrieval rate of words presented auditory and visually. Journal of General Psychology, 112, 201-210.

Collin, C., Wade, D. T., Davies, S., \& Home, V. (1988). The Barthel ADL Index: A reliability study. International Disability Studies, 10(2), 61-63.

Gerritsen, M. J., Berg, I. J., Deelman, B. G., Visser-Keizer, A. C., \& Meyboom-De Jong, B. (2003). Speed of information processing after unilateral stroke. Journal of Clinical and Experimental Neuropsychology, 25, 1-13.

Gronwall, D. M. A., \& Sampson, H. (1974). The psychological effects of concussion. Auckland: Auckland University Press.

Haan, R. (1994). Clinimetrics in stroke (Dissertation). Amsterdam, The Netherlands: University of Amsterdam.

Heaton, R. K., Temkin, N., Dikmen, S., Avitable, N., Taylor, M. J., Marcotte, T. D., \& Grant, I. (2001). Detecting change: A comparison of three neuropsychological methods, using normal and clinical samples. Archives of Clinical Neuropsychology, 16, 75-91.

Hochstenbach, J. (1999). The cognitive, emotional, and behavioural consequences of stroke (Dissertation). Nijmegen, The Netherlands: Catholic University Nijmegen.

Hochstenbach, J., Mulder, T., Van Limbeek, J., Donders, R., \& Schoonderwaldt, H. (1998). Cognitive decline following stroke: A comprehensive study of cognitive decline following stroke. Journal of Clinical and Experimental Neuropsychology, 20, 503-517.

Houx, P. J., Jolles, J., \& Vreeling, F. W. (1993). Stroop interference: Aging effects assessed with the Stroop Color-Word Test. Experimental Aging Research, 19, 204-224.

Jolles, J., Houx, P. J., Van Boxtel, M. P. J., \& Ponds, R. W. H. M. (1995). The Maastricht Aging Study: Determinants of Cognitive Aging. Maastricht, the Netherlands: Neuropsych Publishers.

Krupp, L. B., LaRocca, N. G., Muir-Nash, J., \& Steinberg, A. D. (1989). The Fatigue Severity Scale: Application to patients with multiple sclerosis and systemic lupus erythematosus. Archives of Neurology, 46, 1121-1123.

Owsley, C., Sloane, M., McGwin, G.Jr., \& Ball, K. (2002). Timed Instrumental Activities of Daily Living Tasks: Relationships to cognitive function and everyday performance assessments in older adults. Gerontology, 48, 254-265.

Ponds, R. W. H. M. (1998). Forgetfulness and cognitive aging: Prevalence, characteristics, and determinants (Dissertation). Maastricht, The Netherlands: Maastricht University.

Rasquin, S. M., Lodder, J., Ponds, R. W., Winkens, I., \& Jolles, J. (2004). Cognitive functioning after stroke: A one-year follow-up study. Dementia and Geriatric Cognitive Disorders, 18, $138-144$,

Rasquin, S. M., Verhey, F. R., Lousberg, R., Winkens, I., \& Lodder, J. (2002). Vascular cognitive disorders: Memory, mental speed and cognitive flexibility after stroke. Journal of the Neurological Sciences, 203-204, 115-119.

Reitan, R. M. (1958). Validity of the Trail Making Test as an indicator of organic brain damage. Perceptual and Motor Skills, 8, 271-276.

Salthouse, T. A. (1996). The processing-speed theory of adult age differences in cognition. Psychological Review, 103, 403-428.

Schofield, P. W., Marder, K., Dooneief, G., Jacobs, D. M., Sano, M., \& Stern, Y. (1997). Association of subjective memory complaints with subsequent cognitive decline in community-dwelling elderly individuals with baseline cognitive impairment. American Journal of Psychiatry, 154(5), 609-615. 
Shinar, D., Gross, C. R., Price, T. R., Banko, M., Bolduc, P. L., \& Robinson, R. G. (1986). Screening for depression in stroke patients: The reliability and validity of the Center for Epidemiologic Studies Depression Scale. Stroke, 17, 241-245.

Smith, A. (1982). Symbol Digit Substitution Test (SDMT). Manual (Revised). Los Angeles, CA: Western Psychological Services.

Spikman, J. M., Van Zomeren, A. H., \& Deelman, B. G. (1996). Deficits of attention after closed-head injury: Slowness only? Journal of Clinical and Experimental Neuropsychology, $37,467-478$.

Synchron (1996). Transmuraal Zorgmodel CVA Regio Heuvelland, een model voor de verbetering van kwaliteit van zorg voor CVA-patiënten in de regio Heuvelland (Transmural model for the improvement of care for stroke patients in the region "Heuvelland", the Netherlands). Maastricht, The Netherlands.

Van Exel, J., Koopmanschap, M. A., Van Wijngaarden, J. D. H., \& Scholte Op Reimer, W. J. (2003). Costs of stroke and stroke services: Determinants of patient costs and a comparison of costs of regular care and care organised in stroke services. Cost Effectiveness and Resource Allocation, 1(1), 2.

Van Heugten, C. M. (1998). Apraxia in stroke patients: Assessment and treatment (Dissertation). ctGroningen, The Netherlands: Groningen University.

Van Zomeren, A. H., \& Spikman, J. M. (2003). Tempo en aandacht (Speed and attention). In J. A. M. Vandermeulen, M. M. A. Derix, C. J. J. Avezaat, Mulder, Th. \& J. W. Van Strien (Eds.), Niet aangeboren hersenletsel bij volwassenen [Acquired brain injury in adults]. Maarssen, The Netherlands: Elsvier Gezondheidszorg.

Visser-Keizer, A. C., Meyboom-de Jong, B., Deelman, B. G., Berg, I. J., \& Gerritsen, M. J. (2002). Subjective changes in emotion, cognition and behaviour after stroke: Factors affecting the perception of patients and partners. Journal of Clinical and Experimental Neuropsychology, 24, 1032-1045.

Winkens, I., Van Heugten, C.M., Fasotti, L., Duits, A.A., \& Wade, D.T. (2006). Manifestations of mental slowness in the daily life of stroke patients. Clinical Rehabilitation, 20, 827-34.

Ylvisaker, M., Hanks, R., \& Johnson-Greene, D. (2002). Perspectives on rehabilitation of individuals with cognitive impairment after brain injury: Rationale for reconsideration of theoretical paradigms. Journal of Head Trauma Rehabilitation, 17, 191-209. 


\section{APPENDIX 1}

\section{MENTAL SLOWNESS OBSERVATION TEST}

(Pencil and paper is lying in front of the patient)

General instructions to the subject are as follows:

"I will ask you to perform five tasks that are very similar to tasks that you may encounter in daily life. For example following a route description, making a telephone call, or looking up telephone numbers. I will observe how well you perform the task and I will be timing you. For all the tasks there is one general rule: you are allowed to do anything you would do in normal life to make these tasks easier for yourself".

\section{Subtask 1: Following a route description}

Instruction:

"Imagine you are in an unfamiliar city, and you would like to know where the nearest bakery is. Let's pretend I am a pedestrian, and you decide to ask me. In a minute I will give you a route description. Afterwards, I would like you to draw the route on a map, and tell me where the bakery is [the map will be handed to the patient after the route description is given]. So please make sure that you'll know how to get to the bakery".

Read the following route description to the patient:

"You walk straight on and then take the second turn on your right. When you reach the Bank you go left. Then you take the second turn on your right. You will pass an ancient gate. Keep on walking until you reach a pub, there you turn left. Keep on walking and the bakery will be on your right".

Hand the map to the patient:

"Now try to draw the route on this map. When you are ready, please tell me where the bakery must be".

Time starts when you start reading the route description until the patient shows you on the map where the bakery is. If the patient gets lost and asks for a new route description, take away the map while you read the route description again.

Task materials: paper and pencil, stopwatch, a map, score form.

\section{Subtask 2: Making a telephone call}

Instruction:

"Imagine you would like to visit someone in the University hospital in Maastricht. The visiting hour starts at three o'clock. You leave from the train station in Den Bosch, and travel by public transport. You are now going to call the public transport information service to find out what 
time you have to leave and which train you have to take. This is the telephone number, and this is the question you can ask [hand out paper with information]. Please wait until you can speak to an operator. When you have made the phone call, I will ask you to tell me how you will travel. So make sure you can tell me afterwards. Are you ready? Then you can make the phone call [the patient can read the question from a piece of paper].

Time starts when the operator starts speaking until the patient has reported the information.

Task materials: Piece of paper with the question and phone number, stopwatch, paper and pencil, phone, score form.

\section{Subtask 3: Sorting money}

Instruction:

"In a minute I will ask you to sort from this pile of money 10 precise amounts. The amounts I'm asking for are on this piece of paper [show the paper to the patient]. Every time you have sorted out one amount, please put the money back on the pile. Try to do it as fast as possible. I'll give you five minutes to do this, so try to be ready in time. This watch will keep track of time. The alarm goes off whenever 60 seconds have passed, and every time I will tell you how much time is left. Let's start, shall we?

Time limit: 5 minutes. Time starts when the patient picks up the first coin until he has sorted out the last amount.

Task materials: change, stopwatch, timer, score form, piece of paper with the requested amounts

\section{Subtask 4: listening to the radio news. (This subtask has been excluded from the final version of the MSOT)}

Instruction:

"Imagine you have plans for going to Zandvoort, to the coast, this Saturday and Sunday. You decide to listen to the radio news to find out whether you can expect heavy traffic, what the weather will be like and so forth, so you can decide what you will do and what you have to take with you. In a minute you will listen to a part of the radio news. Afterwards I will ask you some questions. The questions I will ask you are on this piece of paper [show it to the patient]. Listen carefully so you will be able to answer the questions. Do you understand this task? Are you ready to begin?"

Time starts when the radio news starts to play until the patient answers the last question.

Task materials: tape recorder and tape, pen and paper, paper with questions, stopwatch, score form.

\section{Subtask 5: Looking up telephone numbers}

Instruction:

"I will ask you to look up several phone numbers in this phone book. These are the people of whom I'd like to know their phone numbers [show names on a piece of paper]. You can write the numbers down. You have 10 minutes. While you are looking up the phone numbers, I will also ask you several questions you have to answer. At the end of the task I would like you to 
give me all phone numbers. Do you understand what you have to do? Then you may begin with the first phone number".

Time limit: 10 minutes. Time starts when the patient opens the phone book until he/she gives the last phone number.

Task materials: Phone book, list of names, list of questions, paper and pencil, stopwatch, score form.

\section{APPENDIX 2 \\ MENTAL SLOWNESS QUESTIONNAIRE}

Below you see a list of situations that may happen in daily life. For every situation, could you fill in whether this has become a problem due to the stroke? If a certain situation has always been a bit of a problem for you, circle the number 0. If it has worsened, please circle the number that applies to you. The numbers have the following meaning:

$0=$ this never happens to me

$1=$ this rarely happens to me, less than once a week

$2=$ this happens to me now and then, approximately once a week

$3=$ this happens to me frequently, two or three times a week

$4=$ this happens to me often, more often than three times a week

For every question you also fill in how troublesome it is to you when this happens. You can choose between:

not: $\quad$ I do not find this troublesome

fairly: I find this fairly troublesome

very: $\quad$ I find this very troublesome

(Of course, if you fill in that a certain situation never happens to you, you do not have to fill in how troublesome it is to you).

\section{Example}

When someone is talking to me, it takes longer before I understand 012234 what he/she is saying

If it now and then takes longer before you understand what someone is saying. Then you circle the number 2.

How troublesome is this to you?

not fairly very

Perhaps you find it very troublesome that now and then it takes longer before you understand what someone is saying. If this is the case, you circle the word "very". 


\section{WINKENS, VAN HEUGTEN, FASOTTI, AND WADE}

$0=$ never $\quad 1=$ rarely $\quad 2=$ now and then $\quad 3=$ frequently $\quad 4=$ often

Since stroke...

1. When someone is talking to me, it takes longer before I

$\begin{array}{lllll}0 & 1 & 2 & 3 & 4\end{array}$ understand what he/she is saying

How troublesome is this to you?

not fairly very

2. I have trouble keeping up with people (for example, when I am on the phone, or in a meeting

How troublesome is this to you?

$\begin{array}{lllll}0 & 1 & 2 & 3 & 4\end{array}$

not fairly very

3. When I am reading (the newspaper, a book), it takes longer

$\begin{array}{lllll}0 & 1 & 2 & 3 & 4\end{array}$

before I understand what it says

How troublesome is this to you?

not fairly very

4. When I am listening to the radio, or watching television,

I can't keep up with the story

How troublesome is this to you?

$\begin{array}{lllll}0 & 1 & 2 & 3 & 4\end{array}$

not fairly very

5. It takes longer before I come up with the right phone number $\quad \begin{array}{lllll}0 & 1 & 2 & 3 & 4\end{array}$ or word

How troublesome is this to you?

not fairly very

6. When I meet someone in the street, it takes a while

$\begin{array}{lllll}0 & 1 & 2 & 3 & 4\end{array}$

before I remember who it is

How troublesome is this to you?

not fairly very

7. I can no longer perform tasks automatically, I have to think more (when doing household tasks or work)

How troublesome is this to you?

$\begin{array}{lllll}0 & 1 & 2 & 3 & 4\end{array}$

not fairly very

8. I need more time for doing my work or household

$\begin{array}{lllll}0 & 1 & 2 & 3 & 4\end{array}$

tasks, because I have to think more (NOT because of physical disabilities)

How troublesome is this to you?

not fairly very

9. When I am engaged in a task, I feel I have too $\quad 0 \quad 123 \quad 34$ little time to do it right

How troublesome is this to you?

not fairly very

10. If I have to deal with unexpected events,

$\begin{array}{lllll}0 & 1 & 2 & 3 & 4\end{array}$

I get restless or agitated

How troublesome is this to you?

not fairly very 
11. If I do something too fast, I make mistakes or forget

$\begin{array}{lllll}0 & 1 & 2 & 3 & 4\end{array}$

things

How troublesome is this to you?

not fairly very

12. I find it difficult to do two things at the same time

$\begin{array}{lllll}0 & 1 & 2 & 3 & 4\end{array}$ (such as doing household tasks when someone is talking to me, or cooking and making a telephone call at the same time)

How troublesome is this to you?

not fairly very

13. Being in traffic (on foot, by bike or by car) is difficult for me, because I quickly get overwhelmed How troublesome is this to you?

$\begin{array}{lllll}0 & 1 & 2 & 3 & 4\end{array}$ not fairly very

14. When I have to do two things at the same time, I get restless or agitated, or make mistakes

How troublesome is this to you?

$\begin{array}{lllll}0 & 1 & 2 & 3 & 4\end{array}$ not fairly very

15. When I am busy and I am disturbed, (for example, when the phone rings, or someone speaks to me) I start making mistakes

How troublesome is this to you?

not fairly very

16. When I am in a noisy room (e.g., a shop

$\begin{array}{lllll}0 & 1 & 2 & 3 & 4\end{array}$ or pub) I have difficulty paying attention How troublesome is this to you?

not fairly very

17. I get distracted by my own thoughts, and then I

$\begin{array}{lllll}0 & 1 & 2 & 3 & 4\end{array}$ make mistakes

How troublesome is this to you?

not fairly very

18. When several people speak at the same time, (e.g.,

$\begin{array}{lllll}0 & 1 & 2 & 3 & 4\end{array}$ at a party or in a meeting) I lose track of what they are saying

How troublesome is this to you?

not fairly very

19. I get tired easily because everything seems to go so fast How troublesome is this to you?

$\begin{array}{lllll}0 & 1 & 2 & 3 & 4\end{array}$ not fairly very

20. When I have to do two things at the same time, I get tired easily

How troublesome is this to you?

$\begin{array}{lllll}0 & 1 & 2 & 3 & 4\end{array}$

not fairly very

21. If I have to concentrate in a noisy room, I get tired

$\begin{array}{lllll}0 & 1 & 2 & 3 & 4\end{array}$ easily

How troublesome is this to you?

not fairly very 